\title{
Analysis of laminar nanofluid forced convection heat transport through the CFD
}

\author{
Kitae $\mathrm{Yu}^{1}$, Junhyo Kim${ }^{2}$, Jungpil $\mathrm{Noh}^{3}$, Sunchul $\mathrm{Huh}^{4}$, Byeongkeun $\mathrm{Choi}^{5}$, \\ Hanshik Chung ${ }^{6},{ }^{*}$ Hyomin Jeong ${ }^{7}$ \\ ${ }^{1}$ Department of Energy and Mechanical Engineering, Gyeongsang National University \\ ${ }^{2}$ Department of Marine Engineering, Mokpo National Maritime University, 61 dorim-ri,1666 Yeongsan-ro, \\ Cheonggye-myeon, Muan-gun, jeonnam, South Korea \\ ${ }^{3,4,5,6,7}$ Department of Energy and Mechanical Engineering, Gyeongsang National University · Institute of Marine Industry, \\ Cheondaegukchi-Gil 38, Tongyeong, Gyeongnam, 650-160, South Korea
}

\begin{abstract}
In the present paper, developing laminar forced convection flows were numerically investigated by using water$\mathrm{Al}_{2} \mathrm{O}_{3}$ nano-fluid through a circular compact pipe which has $4.5 \mathrm{~mm}$ diameter. Each model has a steady state and uniform heat flux (UHF) at the wall. The whole numerical experiments were processed under the Re $=1050$ and the nano-fluid models were made by the Alumina volume fraction. Single-phase fluid models were defined through nano-fluid physical and thermal properties calculations, Two-phase model (mixture granular model) were processed in 100nm diameter. The results show that Nusselt number and heat transfer rate are improved as the $\mathrm{Al}_{2} \mathrm{O}_{3}$ volume fraction increased. All of the numerical flow simulations are processed by the FLUENT. The results show the increment of thermal transfer from the volume fraction concentration.
\end{abstract}

Keywords—Nanofluid, Alumina, Laminar flow, Mixture, Nusselt number, Heat transfer coefficient, Homogeneous flow.

\section{INTRODUCTION}

To enhance the heat exchangers energy transfer efficiency, Engineers have interested not only the development exchanger or enhanced its structure, but also improvement of heat transfer fluid itself. Maxwell [1] proved the possibility of increasing thermal conductivity of a mixture by higher volume fraction of solid particle. Nowadays available particle diameter is smaller than 100nm which is called 'Nano-sized'. This effort makes particle mixture fluid would enhance the heat transfer performance of heat transfer fluids. [2] Moreover, solid nanoparticle colloids are highly stable and exhibit no significant settling under static conditions. Also, decreasing particle size makes suspending solid colloid easily. So that nano-fluid technology is expected to suitable of heat transfer fluid. [3] However, nano-fluid development is interrupted by the lack of agreement with different research group, theoretical understanding of the heat transfer mechanisms, different suspension conditions. [4]In this paper, Nano-fluid model assume that the Homogeneous flow mixture model [5] which is the dispersed and continuous phase with very strong coupling and the nano-particles is moving at the same inlet velocity. Therefore the dispersed granular mixture models are made by 'Mixture model' which is one of the Euler-Euler approaches. This numerical investigation purpose is an observation of heat transfer coefficient increment in a compact pipe and comparison between single-phase and multi-phase model. Geometry model size is as same as experimental pipe which will use in a university laboratory. Nano-particle volume fractions are less than 5 percent, and divided by 1 percent from 0 to 4 percent. The wall has constant surface heat flux as known as Uniform Heat Flux (UHF). The numerical simulation geometry is asymmetric twodimensional model. Through the limit of 2D model and assumption, implicit effect such as gravity and buoyancy force are excluded. The nano-particle material is an Aluminium Oxide with a spherical size of $100 \mathrm{~nm}$ diameter and simulations are processed in a steady state. The purpose of this study is comparing heat transfer ability between single and mixture model which have same heat transfer value except the particle presence.

\section{Mathematical Modeling}

\subsection{Geometry and boundary condition}

Fig. 1a shows the actual model of geometry and Fig. 1b is the part of the Two-dimensional Mesh. One of the main purpose of this simulation is trying to understand the near wall behavior of nano-particles, velocity distribution perpendicular to the pipe surface and drag coefficient near at the pipe wall, so the relatively concentrated mesh in the near wall area is needed. As a result, the mesh has a non-uniform quadratic mesh. The bottom horizontal line is an axis which makes Three-dimensional pipe model at the asymmetric environment. The upper horizontal line is a wall with UHF. The tube consisted with a diameter (D) of $4.5 \mathrm{~mm}$ and a length ( $\mathrm{L}$ ) of $1.17 \mathrm{~m}$. The nano-fluid is composed of water and $\mathrm{Al}_{2} \mathrm{O}_{3}$ particles. Whole velocity inlet for 
each fluid models enter with uniform temperature and axial velocity profiles are defined by $\operatorname{Re}=1050$. The fluid is flow out to the outflow outlet.

\subsection{Governing equation}

The single-phase model is investigated for the comparison of mixture model as prescribed. Following equations are representing the mathematical formulation of the single-phase model and of the continuous phase of the mixture model. [5-7]

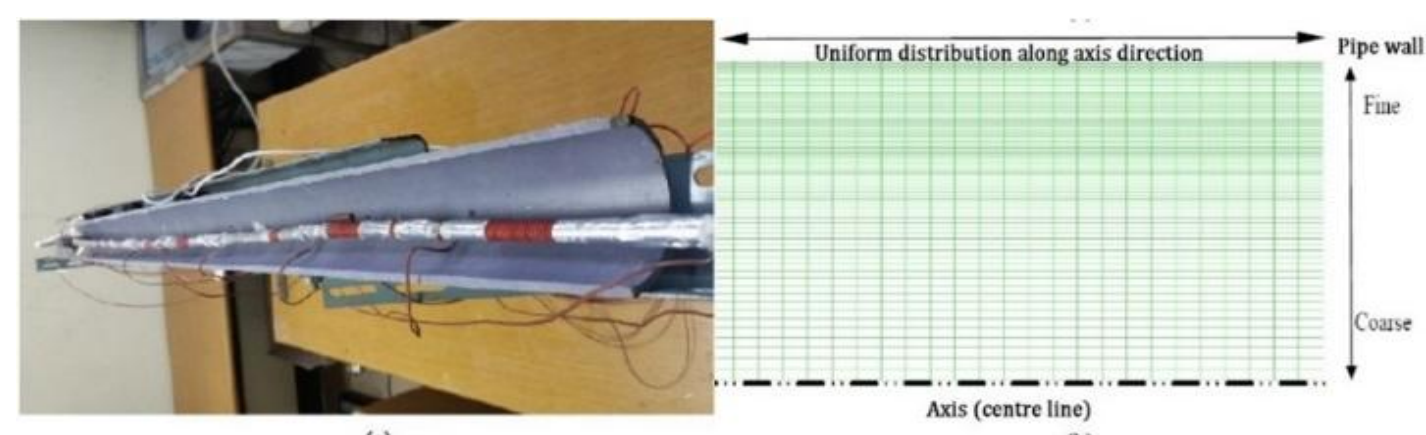

(a)

Figure 1. (A) Actual model of geometry (B) Part of the mesh of Computational Cell. 80 X 8000 WITH 0.96 RATIO

Energy equation

$$
\operatorname{div}(\rho \overrightarrow{\mathrm{V}} \mathrm{CpT})=\operatorname{div}(\operatorname{kgrad} T)+S_{e}
$$

Conservation of mass

$$
\frac{\delta \rho_{m}}{\delta t}+\nabla \cdot\left(\rho_{m} u_{m}\right)=0
$$

Mass-averaged velocity $u_{m}$ is

$$
u_{m}=\frac{\sum_{k=1}^{n} \alpha_{k} \rho_{k} u_{k}}{\rho_{m}}
$$

and $\rho_{m}$ is the mixture density with $\alpha_{k}$ volume fraction of phase $k$

$$
\rho_{m}=\sum_{k=1}^{n} \alpha_{k} \rho_{k}
$$

Momentum equation for single-phase

$$
\operatorname{div}(\rho \overrightarrow{\mathrm{V} V})=-\operatorname{grad} P+\nabla \cdot(\mu \nabla \overrightarrow{\mathrm{V}})+S_{m}
$$

Momentum equation for multi-phase

$$
\nabla \cdot \sum_{k=1}^{n} \alpha_{k} \rho_{k} u_{k} u_{k}=\nabla \cdot\left(\rho_{m} u_{m} u_{m}\right)+\nabla \cdot \sum_{k=1}^{n} \alpha_{k} \rho_{k} u_{M k} u_{M k}
$$

The compression and viscous lose by heat are assumed to be excluded in the energy equation. The source/sink terms $S_{m}$ and $S_{e}$ represent the unitive effects of energy and momentum exchange with base fluid. These are zero value in the single-phase model. Momentum equation of multi-phase are affected by volume fraction $(\alpha)$, velocity of phase $\left(u_{k}\right)$, diffusion velocity $\left(u_{M k}\right)$. The determinations of particle motion are particle density $\left(\rho_{c}\right)$, cross-sectional area of the particle $\left(\mathrm{A}_{p}\right)$, drag coefficient $\left(\mathrm{C}_{D}\right)$, slip velocity $\left(u_{c p}\right)$. The drag force in this study is following Clift et al equation (7) for single rigid spherical particle in a fluid.

$$
\mathrm{F}_{D}=-\frac{1}{2} A_{p} \rho_{c} C_{D}\left|u_{C p}\right| u_{C p}-\frac{1}{2} V_{p} \rho_{c} \frac{d u_{C p}}{d t}-6 \gamma_{p}^{2} \sqrt{\pi \rho_{c} \mu_{c}} \int_{0}^{t} \frac{\frac{d u_{C p}}{d s}}{\sqrt{t-s}} d s
$$

The drag coefficient which is already showed in equation (7) depends on small Particle Reynolds numbers with particle Reynolds number

$$
\mathrm{C}_{D, S t}=\frac{24}{R e_{p}}
$$

The slip velocity is following equation (9) with $\tau_{p}$ the particle relaxation time, $\vec{a}$ is the secondary-phase particle's acceleration

$$
\mathrm{u}_{p q}=\frac{\tau_{p}\left(\rho_{p}-\rho_{m}\right)}{f_{\text {drag }}} \vec{a}
$$


The default drag function is taken Schiller and Naumann. Reynolds numbers in this paper are over 1000 so the equation is defined as follow

$$
f_{\text {drag }}=0.0183 \mathrm{Re}
$$

\subsection{Physical properties of the nanofluid for single-phase model and Boundary conditions}

At inlet boundary condition, axial velocity $\mathrm{V}_{0}$ is defined from $\mathrm{Re}=1050$ according to the fluid properties and a constant temperature $(293 \mathrm{~K})$ as described. On the tube wall, the usual non-slip conditions and uniform wall heat flux $q=5000 \mathrm{~W} / \mathrm{m}^{2}$ are implemented.The determination of nano-fluid physical, thermal properties are at the center of current nano-fluids research as previously mentioned.[7] For the single phase model properties of the nano-fluids have been calculated by using classical formulas developed for conventional solidliquid mixtures.[8] The following equations are considered to evaluate Al2O3-water nano-fluids thermo-physical properties and were used for CFD simulation.[6,9]

$$
\begin{gathered}
\rho_{n f}=(1-\varphi) \rho_{b f}+\varphi \rho_{p} \\
c_{p, n f}=\frac{(1-\varphi)\left(\rho c_{p}\right)_{b f}+\varphi\left(\rho c_{p}\right)_{p}}{\rho_{n f}} \\
\mu_{n f}=(1+2.5 \varphi) \mu_{b f}
\end{gathered}
$$

The $\varphi$ is the volume fraction of the $\mathrm{Al}_{2} \mathrm{O}_{3}$. The dynamic viscosity that temperature depended properties are excluded and has a constant value. Determination of nano-fluid effective thermal conductivity as follow. [10]

$$
k_{n f}=\left[\frac{k_{s}+2 k_{w}+2\left(k_{s}-k_{w}\right)(1+\beta)^{3} \varphi}{k_{s}+2 k_{w}-\left(k_{s}-k_{w}\right)(1+\beta)^{3} \varphi}\right] k_{w}
$$

In Equation (14), $\beta$ is the ratio of nano-layer thickness to the original particle radius, and $\beta=0.1$ is used for calculation in this equation. The result of physical and thermal properties of nano-fluid models are presented in Table 1 and $\mathrm{Al}_{2} \mathrm{O}_{3}$ particle physical and thermal properties as follow in Table 2

\section{$2.4 \quad$ Numerical approach}

The computational fluid dynamic code FLUENT 16.1 is employed to solve the present problem. The governing Eqs. (1)-(3) are solved by control volume approach. For the convective and diffusive terms, a second order upwind method was used. Pressure and velocity were coupled using Semi Implicit Method for Pressure Linked

\section{TABLE 1}

PROPERTIES OF NANO-FLUID AT 293K AND RE $=1050$

\begin{tabular}{|c|c|c|c|c|c|}
\hline $\boldsymbol{\Phi}(\boldsymbol{\%})$ & Density $\left(\mathbf{k g} / \mathbf{m}^{\mathbf{3}}\right)$ & Viscosity $(\mathbf{k g} / \mathbf{m s})$ & $\begin{array}{c}\text { Inlet } \\
\text { velocity }(\mathbf{m} / \mathbf{s})\end{array}$ & $\begin{array}{c}\text { Heat } \\
\text { conductivity }(\mathbf{W} / \mathbf{m K})\end{array}$ & $\begin{array}{c}\text { Specific } \\
\text { heat }(\mathbf{J} / \mathbf{k g K})\end{array}$ \\
\hline $\mathbf{0}$ & 998.2 & $9.98 \mathrm{e}-4$ & 0.233 & 0.5970 & 4182.0 \\
\hline $\mathbf{1}$ & 1027.018 & $1.023 \mathrm{e}-3$ & 0.2324 & 0.6200 & 4053.21 \\
\hline $\mathbf{2}$ & 1055.836 & $1.048 \mathrm{e}-3$ & 0.2316 & 0.6436 & 3931.451 \\
\hline $\mathbf{3}$ & 1084.654 & $1.073 \mathrm{e}-3$ & 0.2308 & 0.6678 & 3816.162 \\
\hline $\mathbf{4}$ & 1113.472 & $1.098 \mathrm{e}-3$ & 0.2300 & 0.6926 & 3706.840 \\
\hline
\end{tabular}

TABLE 2

$\mathrm{Al}_{2} \mathrm{O}_{3}$ NANOPARTICLE AT TEMPERATURE OF 293K

\begin{tabular}{|c|c|c|c|}
\hline Density $\left(\mathbf{k g} / \mathbf{m}^{3}\right)$ & Heat conductivity $(\mathbf{W} / \mathbf{m K})$ & Specific heat $(\mathbf{J} / \mathbf{k g K})$ & Spherical diameter(nm) \\
\hline 3880 & 36 & 773 & 100 \\
\hline
\end{tabular}

Equations (SIMPLE) in single-phase. Unlike single-phase, multi-phase was approached by Coupled algorithm which offers an alternative to the density-based and pressure-based segregated algorithm with SIMPLE-type pressure-velocity coupling. The difference between SIMPLE and Coupled is a Convergence time [6] and Couple algorithm has converged faster than SIMPLE in multi-phase. The laminar flow has fully developed region that distribution of flow velocity maintains constant. In this study, fully developed region appears after $0.307 \mathrm{~m}$ according to equation (15). [12].

$$
\mathrm{L}_{\text {laminar }}=0.065 \cdot R e \cdot D
$$


The velocity distributions are showed in Figure 2. It is only 0.6737 percent less than outlet at an axial velocity at the $0.307 \mathrm{~m}$ in Fig. 2a and all mixture models are following the Fully developed region in Fig. 2b. This means nano-fluid motion is fully developed at exit section model, when properties are not dependent on temperature, velocity profile and hydrodynamic entrance length are nearly identical at $0.307 \mathrm{~m}$ for $\Phi=0 \%, 1 \%, 2 \%, 3 \%$ and $4 \%$.[7]A Nusselt number is converged to 4.36 in the UHF.[13] Comparing Nusselt number to Churchill-Ozoe equation (16) [14] and Siegel Sparrow-Hallman calculation equation (17) [15] and common Nusselt number equation (18) which used in present study in Figure 3. $x^{*}$ is a dimensionless axial position for thermally developing flows. $\operatorname{Pr}$ is the Prandtl number.

$$
\begin{aligned}
\mathrm{Nu} & =5.364\left[1+\left(70.0 x^{*}\right)^{-10 / 9}\right]^{3 / 10}-1 \\
N u & =\frac{2}{\left[\left(\frac{t_{w}-t_{0}}{q r_{0} / k}\right)-\left(\frac{4 x / r_{0}}{R e P r}\right)\right]} \\
N u & =\frac{h(x) D}{k_{\text {inlet }}}
\end{aligned}
$$

The heat transfer coefficient $\mathrm{h}(\mathrm{x})$ is defined as

$$
\mathrm{h}(x)=\frac{q}{T_{w}(x)-T_{b}(x)}
$$

The $T(x)_{w}$ is the solid surface temperature at the wall temperature, and $T(x)_{b}$ is the mean bulk temperature. Average Nusselt number is defined as

$$
\mathrm{Nu}_{a v}=\frac{h_{a v} \cdot D}{k_{\text {inlet }}}
$$

Current study model on $\varphi=0 \%$ is going to 4.69 Nusselt number which has a 7 percentage point gap between normal convergence value. Therefore velocity distribution and Nusselt number show the model has fitted in the theory.

\section{RESUltS}

In this work a number of numerical simulations have been performed to study forced convective heat transfer of $\mathrm{Al}_{2} \mathrm{O}_{3}$-water in a circular tube under laminar flow and results were conducted to employing the single phase and mixture model for $\varphi=1 \%$ to $4 \%, \operatorname{Re}=1050$ as $q=5000 \mathrm{~W} / \mathrm{m}^{2}$ with a constant state. In all cases the size of the spherical particles is 100 $\mathrm{nm}$.
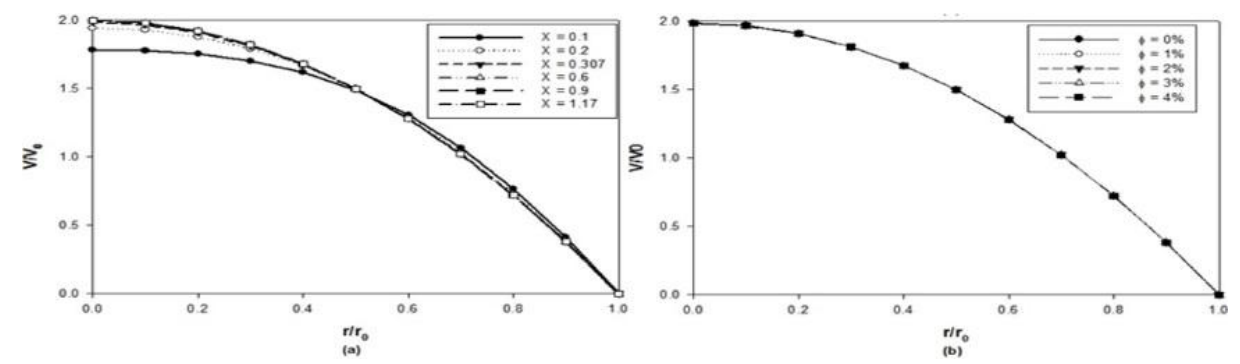

Figure 2. (a) Profiles of AXIAL Velocity AT SEVERAL locations FOR $\operatorname{Re}=1050, q=5000 \mathrm{~W} / \mathrm{m}^{2}, \Phi=$ 4\%. (b) PROFILES OF AXIAL VELOCITY AT $x=0.307 \mathrm{~m}$ for $\mathrm{Re}=1050, \mathrm{q}=5000 \mathrm{~W} / \mathrm{m}^{2}$ AND SEVERAL VOLUME FRACTIONS.

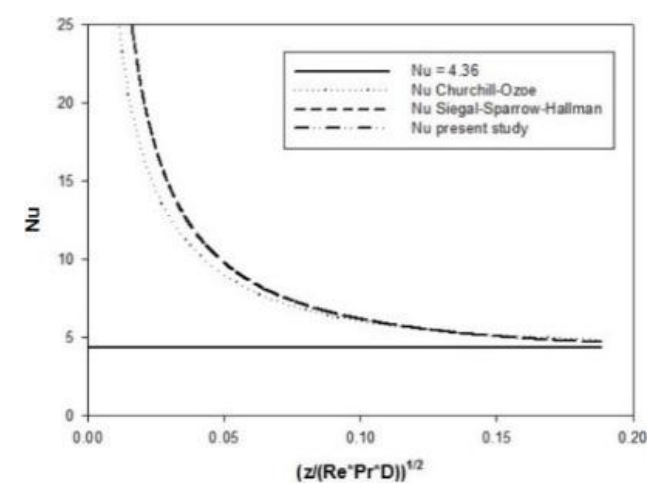

Figure 3. GRID VALIDATION BY MEANS OF CHURCHILl AND OZOE, SiEgal-SPaRROW-HALlMAN 
Dimensionless temperature shows the particle concentration increase happens the thermal development acceleration of the fluid at several axial locations along the radius is reported in Fig. 4 for $\boldsymbol{\varphi}=\mathbf{0} \%$ and $\mathbf{4} \%$. For the both the base fluid and the nano-fluid, the motion is not thermally developed. As it is also noticed by a higher slope of relative local heat transfer coefficient $h_{r}$ for $\boldsymbol{\varphi}=\mathbf{4} \%$ shown in Fig. 5a.Relative local heat transfer coefficient is increasing with axis location and volume fraction rise when fluid properties are constant in Fig. 5a. Because of narrow hydrodynamic radius of model, correlation between wall and bulk temperature is higher than larger model. Consequently, difference between the wall and bulk temperature is decrease and with the heat flux on the wall being constant, there is an increase in the heat transfer coefficient, as shown in Fig. $5 b$.

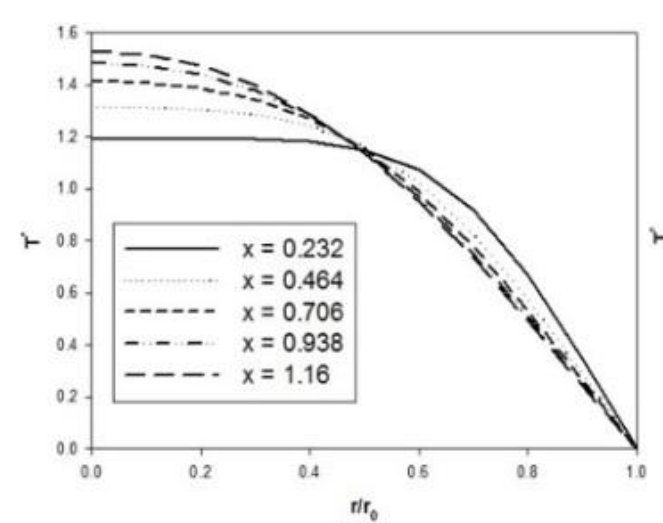

(a)

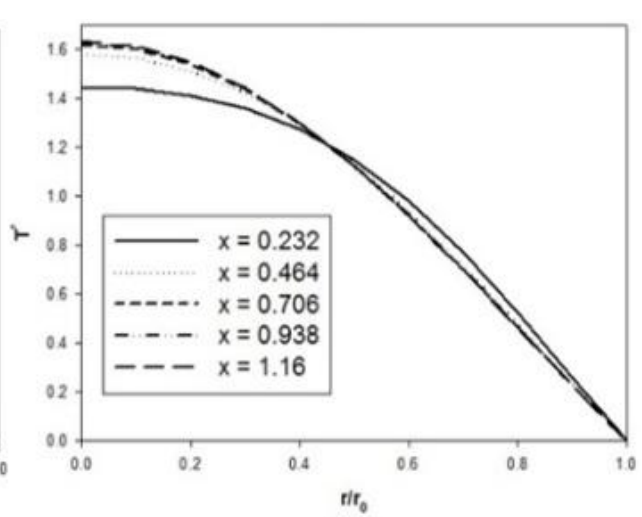

(b)

FIGURE 4. DIMENSIONLESS TEMPERATURE FOR $R=1050$ and $q=5000 \mathrm{~W} / \mathrm{m} 2$ AT SEVERAL LOCATIONS FOR : (a) $\Phi=0 \%$ and (b) $\Phi=4 \%$

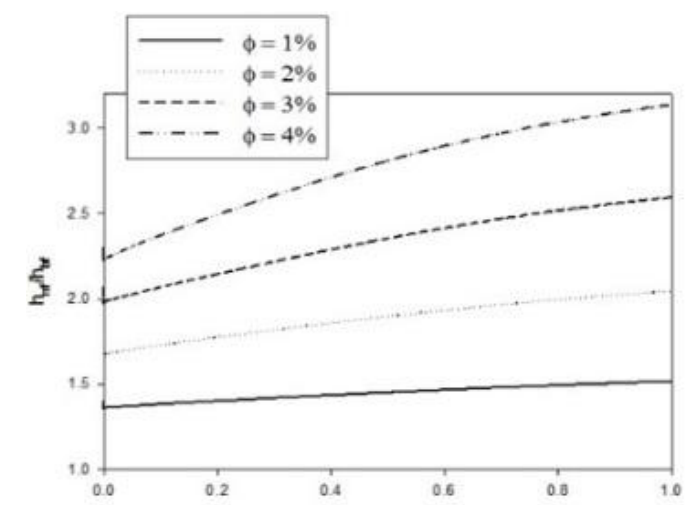

(a)

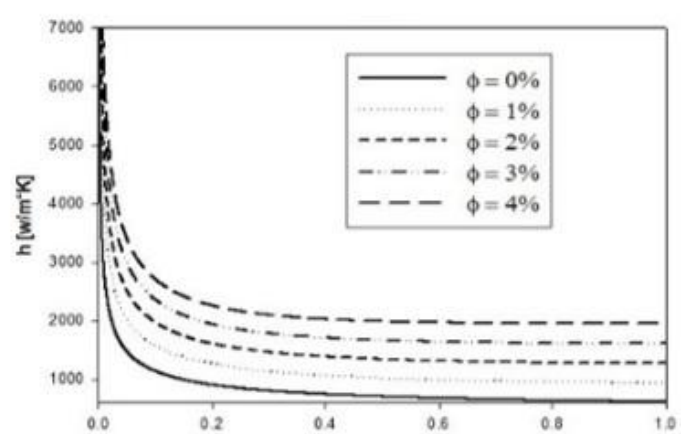

(b)

FIGURE 5. (A) INCREASE IN NANO-FLUID HEAT TRANSFER COEFFICIENT ALONG TUBE AXIS FOR Re = 1050 and $q=5000 \mathrm{~W} / \mathrm{m}^{2}$ FOR CONSTANT PROPERTIES AND INCREMENT OF VOLUME FRACTION. (B) HEAT TRANSFER COEFFICIENT OF EACH VOLUME FRACTION FOR CONSTANT PROPERTIES.

In Fig. 6, radial temperature profiles at profiles at $x / L=1.0$ for $\mathrm{Re}=1050$ and $q=5000 \mathrm{~W} / \mathrm{m}^{2}$ are investigated for the effect of particle presence. The temperature is strongly dependent on $\varphi$ concentration. When the multi-phase concentration increases, the difference between temperature at surface and axis decrease by higher forced convection heat transfer. This effect is the cause of wall temperature decrease. It is also implemented in single-phase however, due to the particle absence, heat transfer between wall and inner side is not remarkable. Furthermore the only average temperature $1.3 \mathrm{~K}$ increase than $293 \mathrm{~K}$ on single-phase models. Both of phase show there is a clear existence of a uniform temperature fluid zone that becomes more visible for higher value of $\Phi$ at the $r / r_{0}=0.6$.

\section{CONCLUSION}

Average heat transfer coefficient and Nusselt number are shown in Table 3 with relative increase of the total heat transfer rates and Nusselt number as a concentration of the nano-particle volume fraction $\varphi$. Significant increases of the total heat transfer rates can be found with the use of fully dispersed nanoparticles multi-phase. These results have indicated the nanofluids beneficial effects of thermal properties improvement. The results showed that the nanoparticles inclusion produced considerable heat transfer with respect to base fluid. Heat transfer enhancement was increasing with concentration of particle 
volume. But the CFD should be progressed with constant and transient numerical investigation parallel and these numerical researches would be pace with the experiment especially.

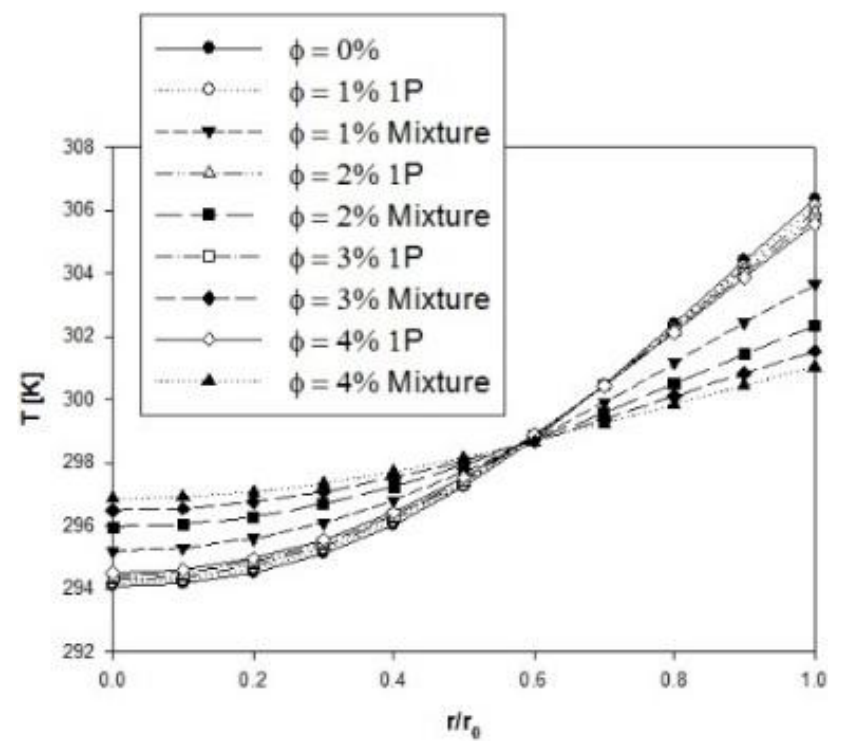

FIGURE 6. COMPARISON OF TEMPERATURE ALONG TUBE RADIUS AT $\mathrm{x} / \mathrm{L}=0.99$ FOR SEVERAL CONCENTRATION AND FOR $R e=1050$ and $q=5000 \mathrm{~W} / \mathrm{m}^{2}$ IN CONSTANT PROPERTIES

TABLE 3

HEAT TRANSFER COEFFICIENTS FOR Re $=1050, q=5000 \mathrm{~W} / \mathrm{m}^{2}$ AND THE INVESTIGATED MODELS

\begin{tabular}{|c|c|c|c|c|}
\hline$\Phi(\%)$ & $\mathbf{h}_{\mathbf{a v}}(\mathbf{W} / \mathbf{m K})$ & $\mathbf{h}_{\mathbf{n f}} / \mathbf{h}_{\mathbf{b f}}$ & $\mathbf{N u}_{\mathbf{a v}}$ & $\mathbf{N u}_{\mathbf{n f}} / \mathbf{N u}_{\mathbf{b f}}$ \\
\hline $\mathbf{0}$ & 861.815 & 1 & 6.5 & 1 \\
\hline $\mathbf{1}$ & 1233.288 & 1.431 & 8.95 & 1.377 \\
\hline $\mathbf{2}$ & 1592.853 & 1.848 & 11.1 & 1.707 \\
\hline $\mathbf{3}$ & 1954.472 & 2.268 & 13.2 & 2.027 \\
\hline $\mathbf{4}$ & 2301.521 & 2.671 & 14.9 & 2.302 \\
\hline
\end{tabular}

\section{ACKNOWLEDGMENTS}

This research was supported by Basic Science Research Program through the National Research Foundation of Korea(NRF) funded by the Ministry of Education(No. 2015R1D1A1A01058030).

\section{REFERENCES}

[1] J. C. Maxwell, A Treatise on Electricity and Magnetism, Oxford University Press, Cambridge, 1881

[2] Taylor, R. A, Small particles, big impacts: A review of the diverse applications of nanofluid, Journal of Applied Physics 113, pp. 1, 2013

[3] S. M. S. Murshed, K. C. Leong, C. Yang, Thermophysical and electrokinetic properties of nanofluids - a critical review, Applied Thermal Engineering 28, pp. 2109-2125, 2008

[4] X. Q. Wang, A. S. Mujumdar, Heat transfer characteristics of nanofluids: a review, International Journal of Thermal Sciences 46, pp. 1-19, 2007

[5] Mi. Manninen, V. Taivassalo, S. Kalliio, On the mixtrue model for multiphase flow, Valtiion Teknillinen Tutkmuskeskus, 1996

[6] ANSYS Fluent Theroy Guide, pp. 501, November 2013

[7] V. Bianco, F. Chiacchio, O. Manca, S. Nardini, Numerical investigation of nanofluids forced convection in circular tubes, Applied Thermal Engineerinig 29, pp. 3632-3642, 2009

[8] S. K. Das, S. U. S. Choi, W. Yu, and T. Pradeep, Nanofluids Science and Technology, John Wiley \& Sons, Hoboken, Nj, USA, 208

[9] S. Z. Heris, M. N. Esfahancy, and S. G. Etemad, Experimental investigation of convective heat transfer of Al2O3/water nanofluid in circular tube, International Journal of Heat and Fluid Flow 28, pp. 203-210, 2007'. 
[10] S. J. Kline and F. A. McClintock, Mechanical Eng. 75, 3, 1953

[11] M. Nazififard, M. Nematollahi, K.Jafarpur, K. Y. Suh, Numerical Simulation of Water-Based Alumina Nanofluid in Subchannel Geometry, Science and Technology of Nuclear Installations, Vol 2012, 2012

[12] Kominu Natsuo, Fluid Engineeriing, Syuwa system, pp. 176, 2006

[13] Mohammad Z. Hasan, Effects of non-uniform surface heat flux and uniform volumetric heating on blanket design for fusion reactors, Fusion Science and Technology, Los Angeles, May 1988

[14] S. W. Churchill, H. Ozoe, Correlations for forced convection with uniform heating in flow over a plate and in develooping and fully developed flow in a tube, Journal of heatTrnasfer 95, pp. 78-84, 1973

[15] R. Siegel, E. M. Sparrow, T. M. Hallman, Steady laminar heat transfer in a circular tube with prescibed wall heat flux, Cleveland, Ohio, UA, Aplied Scientific Research, Section A, Volume 7, Issue 5, pp. 386-692, September, 1958 